Article

\title{
Bearing Thickness Is Not a Predictive Factor for Damage and Penetration in Oxford Unicompartmental Knee Arthroplasty-A Retrieval Analysis
}

\author{
Johannes Adrian Eckert $^{\dagger}$, Ulrike Mueller ${ }^{\dagger}\left(\mathbb{D}\right.$, Tilman Walker, Martin Schwarze ${ }^{(D)}$ \\ Sebastian Jaeger and Jan Philippe Kretzer* \\ Laboratory of Biomechanics and Implant Research, Clinic for Orthopedics and Trauma Surgery, \\ Heidelberg University Hospital, Schlierbacher Landstraße 200a, 69118 Heidelberg, Germany; \\ Johannes.Eckert@med.uni-heidelberg.de (J.A.E.); ulmuel@hotmail.de (U.M.); \\ Tilman.Walker@med.uni-heidelberg.de (T.W.); Martin.Schwarze@med.uni-heidelberg.de (M.S.); \\ Sebastian.Jaeger@med.uni-heidelberg.de (S.J.) \\ * Correspondence: philippe.kretzer@med.uni-heidelberg.de \\ † These authors contributed equally.
}

Received: 19 August 2020; Accepted: 13 October 2020; Published: 15 October 2020

\begin{abstract}
The medial Oxford unicompartmental knee arthroplasty (OUKA) shows good survivorship, as well as clinical results. Aseptic loosening, however, remains one of the main reasons for revision and polyethylene debris is known to cause aseptic loosening. The role of bearing thickness in total as well as unicondylar knee arthroplasty has been the subject of controversial discussions, especially the longevity of lower thickness bearings in total knee arthroplasty was questioned. The purpose of this study was to assess the influence of bearing thickness on time to revision, damage pattern, penetration, and volumetric material loss. A cohort of 47 consecutively retrieved medial OUKA bearings was analyzed with conventional direct light microscopy applying the Hood damage analysis, as well as measuring the penetration depth. In this retrieval cohort, a difference on survival time, damage, penetration, as well as volumetric material loss could not be seen. We conclude that low as well as high thickness bearings can safely be used in OUKA without any relevant differences in terms of wear and damage.
\end{abstract}

Keywords: oxford unicompartmental knee arthroplasty; bearing thickness; retrieval analysis

\section{Introduction}

The Oxford unicompartmental knee arthroplasty (OUKA) has been shown to generate good clinical results. Due to the increased use of highly crosslinked polyethylene (HXLPE), the number of revisions due to wear has decreased [1-3] (the Annual Report of the Australian National Joint Registry notes only $1.4 \%$ of direct tibial insert wear [4]). However, aseptic loosening-which can be caused by wear-is still the major cause for revisions of UKA [4,5], the 15-year revision rate is around $11 \%$ [6]. The use of a spherical femoral component and a fully congruous meniscal bearing to increase the contact area theoretically reduces the potential for polyethylene wear [7]. Mobile bearing unicondylar designs, however, can exhibit wear at the femoral, as well as the tibial aspect of the inlay [8,9]. Especially in cases of suboptimal bearing positioning, the wear can increase drastically [10]. To date, there is no scientific consent as to which inlay thicknesses generate better outcomes. Longer times to revision in Oxford UKA have been described for 3 and $4 \mathrm{~mm}$ bearings, respectively, compared to thicker bearings [10]. In addition, the use of thinner inlays allows for a reduced loss of bonestock and usage 
of thicker bearings has a higher risk for overcorrection of the mechanical axis, resulting in a higher post-operative valgus [11]. In incongruent articulations, however, the wear rate of polyethylene is increased when it is used in a thin layer [12,13], and bearing failures have been described for inlays $<6 \mathrm{~mm}$, caused by wear $[14,15]$. Accordingly, the FDA has issued a Class II Special Controls Guidance Document in 2003, recommending a minimum thickness of $6 \mathrm{~mm}$ at the lowest point below the condyle (or alternatively the demonstration of the ability of the said bearing to survive 10 million cycles in a physiological knee simulator). Unfortunately, the information provided by manufacturers with regards to the actual inlay thickness often appears to be inaccurate or misleading [16].

In this retrieval analysis of a series of 47 consecutively explanted medial Oxford unicondylar knee replacements, we assessed the types of damage using the modified Hood score and analyzed penetration depth and volumetric changes during the lifetime of the retrieved bearings [17]. We wanted to assess whether the use of higher-thickness inlays (5-6 mm in this cohort) leads to higher wear than the use of low-thickness inlays (3-4 mm) and if different types of damage are seen in the two groups.

\section{Materials and Methods}

From October 2013 to August 2018, 47 ultra-high molecular weight polyethylene (UHMWPE) meniscal bearings of the medial Oxford unicompartmental knee arthroplasty (OUKA) from 46 patients were consecutively explanted and included in this retrieval analysis. All retrievals were conducted at our hospital. Of the 47 inlays, the majority $(n=41)$ was of the newer 'anatomic' generation, only six were old type inlays. Eight of the inlays were small (all anatomic), 19 were medium-sized (16 anatomic, three non-anatomic), and 20 were large (17 anatomic, three non-anatomic). No XS inlays were explanted in the period examined. Of the revised knees, 21 were left knees, 26 were right knees. In 38 cases, the primary procedure was performed in our hospital, the remaining eight procedures were performed elsewhere. Primary implantations were conducted from October 2002 to September 2017. The manufacturer changed the type of UHMWPE in 2005. In this cohort, five of the retrieved inlays were implanted before, the rest after the change in material. The UHMWPE used before 2005 was Hi-Fax 1900, the PE currently in use is GUR 1050. A publication by Mohammad et al. showed no significant differences in wear between the two types of UHMWPE using a RSA analysis [18]. Microscopical images of the types of damage were made using a Keyence VHX-5000 reflected-light microscope.

The reasons for revision in descending order were progression of disease in other compartments $(n=19 ; 30 \%)$, followed by aseptic loosening $(n=9 ; 14 \%)$ and bearing dislocation $(n=5 ; 8 \%)$. Other reasons for revision were periprosthetic fractures, persistent postoperative pain, instability, infection, etc.

Following an institutional review board (IRB)-approved protocol, all orthopedic devices were collected, cleaned, and cataloged in an electronic database for long-term storage in an inert environment.

Surface damage of the retrieved meniscal bearings was assessed using light stereomicroscope analysis at magnifications from $\times 10$ to $\times 20$. The tibial bearings were divided into three regions (front-anterior, front-posterior, and back; see Figure 1). For these regions, the wear was quantified using the modified Hood-method [17], a method which has since been used for most macroscopic retrieval analyses $[19,20]$. Eight types of damage were assessed: Burnishing, scratching, pitting, delamination, surface deformation, abrasion, third-body embedded debris, and edge loading (Figure 2). Grading was performed by two graders (JAE, JPK) blinded to the clinical and radiographic data. Scores of 1, 2, and 3 indicated damage areas of $<10 \%, 10 \%$ to $50 \%$, and $>50 \%$ of the surface area, respectively. The total score for each bearing was the sum of the eight individual damage scores over the three zones. The maximum score for each surface was 72 . 


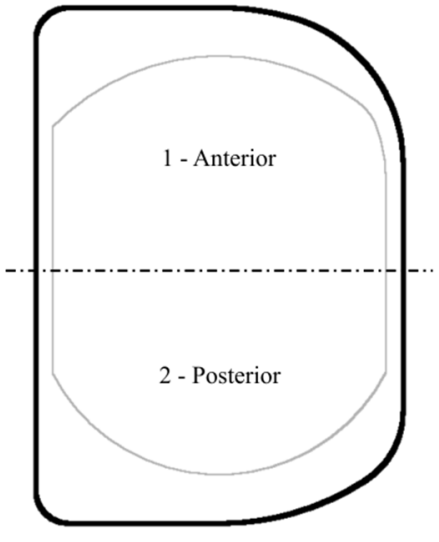

Front

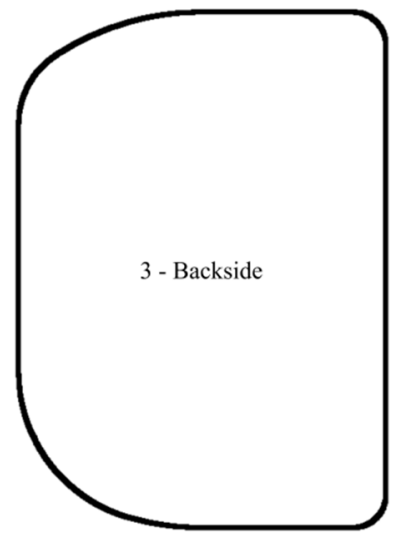

Back

Figure 1. The front and back of the meniscal bearings were divided into three sections. Surface damage grading scores were assigned for each section using light stereoscopic examination and a subjective grading score.
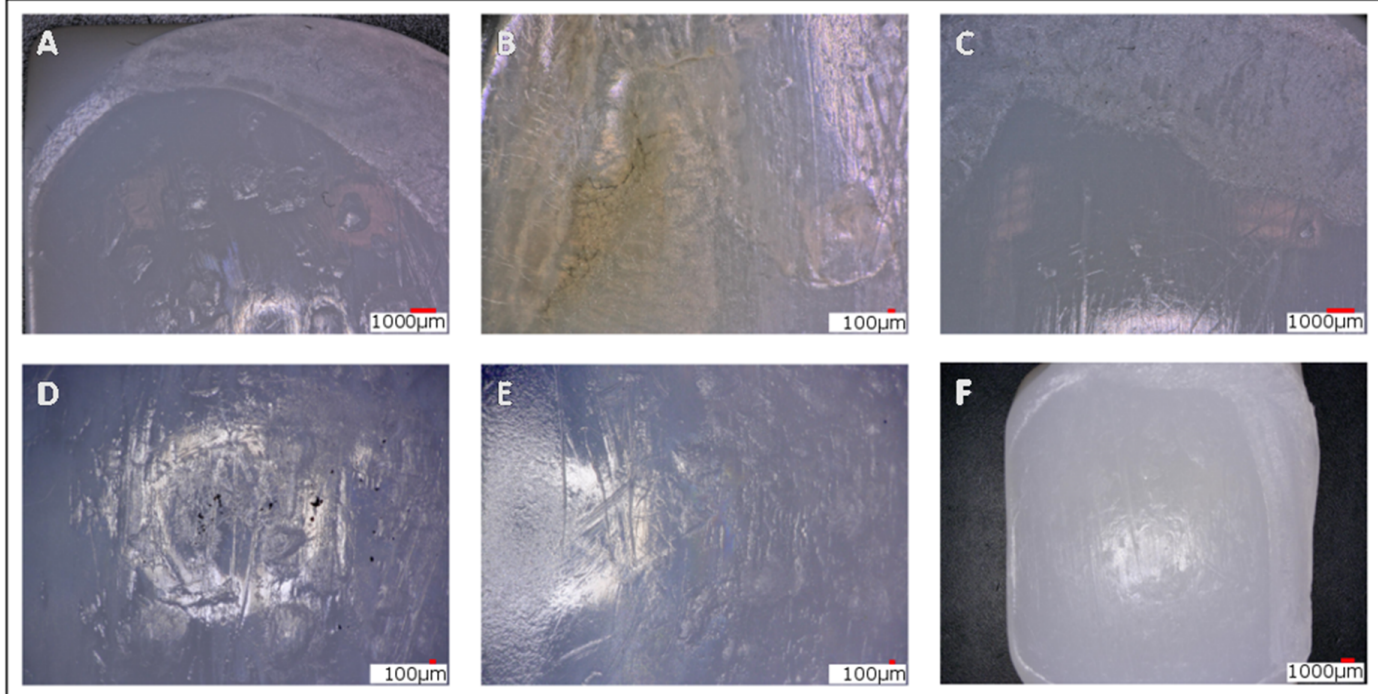

Figure 2. (A) Edge loading and abrasion in the anterior medial border of the inlay, pitting throughout the inlay, small scratches; (B) delamination at the anterior medial border of the inlay (noticeable at the brown change in color little pitting and scratching; (C) abrasion, scratching, and little pitting; (D) embedded particles (small black dots, possibly metal debris), a lot of scratching and pitting; (E) burnishing (see changes of regular manufacturing marks on the left side to a polished surface);

(F) surface deformation, edge loading, abrasion, and a little pitting and scratching.

The thicknesses of the tibial bearings as specified by the manufacturer for the current implant design of the OUKA range from 3 to $9 \mathrm{~mm}$. The thicknesses of the retrieved bearings in this study ranged from 3 to $6 \mathrm{~mm}, 3$ and $4 \mathrm{~mm}$ inserts were classified as low thickness inserts, 5 and $6 \mathrm{~mm}$ were classified as high thickness inserts. The manufacturer does not further specify the thicknesses, however, the nominal thickness of each bearing is always bearing thickness $+0.5 \mathrm{~mm}$. The mean variance of $+0.130 \mathrm{~mm}$ was added, as the nominal thickness does not resemble the true thickness of a new inlay. We have found a mean variance of $+0.130 \mathrm{~mm}$ in 10 brand new inlays, measured for this purpose.

To establish the linear penetration, the minimum thickness of each retrieved bearing was subtracted from the initial bearing thickness. The thickness was measured using a digital dial gauge (MarCator 1075 R, Mahr, Göttingen, Germany). A similar dial-gauge technique was reported by Psychoyios et al. to determine the minimum thickness of similar bearings [21]. Each bearing was 
mounted on a precision comparator stand with a universal measuring arm and a probe with a spherical tip of $4 \mathrm{~mm}$ in diameter was used. The dial gauge was determined to have a mean error of $0.0005 \mathrm{~mm}$. Each bearing was measured once by two independent observers (JAE and JPK) and the mean of these values was taken as the minimum thickness of the bearing surface. Linear penetration was then calculated using the following formula:

Linear penetration $(\mathrm{LP})(\mathrm{mm})=\mathrm{TN}+\mathrm{TC}-\mathrm{TR}$

$\mathrm{TN}=$ Nominal thickness $=$ Bearing size $+0.5 \mathrm{~mm}$

$\mathrm{TC}=$ Tolerance correction thickness $=0.13 \mathrm{~mm}$

$\mathrm{TR}=$ Thickness at retrieval $=$ Measured thickness $(\mathrm{mm})$

As the inlay is a fully congruent bearing, covered in the backside base area by the tibial plate and in the top area by the femoral component, the approximated volumetric wear rate was additionally assessed as follows:

Approximated volumetric wear rate $(\mathrm{AWR})=(($ base area + top area $) / 2) \times \mathrm{LP}$.

The base areas were established dependent on the size and the design (anatomic/non-anatomic) of the bearing. Due to the necessity of a correction factor, especially in short time periods to revision, a negative approximated volumetric change-meaning an increase in thickness of the retrieved bearing-can occur. This was the case for $n=4$ bearings (IDs 126, 199, 268, 1168). Four other inlays (IDs 92, 100, 675, 1092) had a time to revision $<1$ month. These eight bearings were excluded from the analysis of the penetration rate, as well as the approximated volumetric change.

\section{Results}

The data collected showed a comparable result between the two independent examiners $(R=0.82)$. The predominant type of damage was burnishing, followed by scratching and pitting. Edge loading, abrasion, and surface deformation were less common, while delamination and embedded particles were seen very rarely (Figure 3). Burnishing showed the highest number for all portions of the bearing, scratching-while seen in every specimen-was equally distributed over the Hood score. Pitting was also evenly distributed, yet some inlays did not exhibit any signs of pitting.

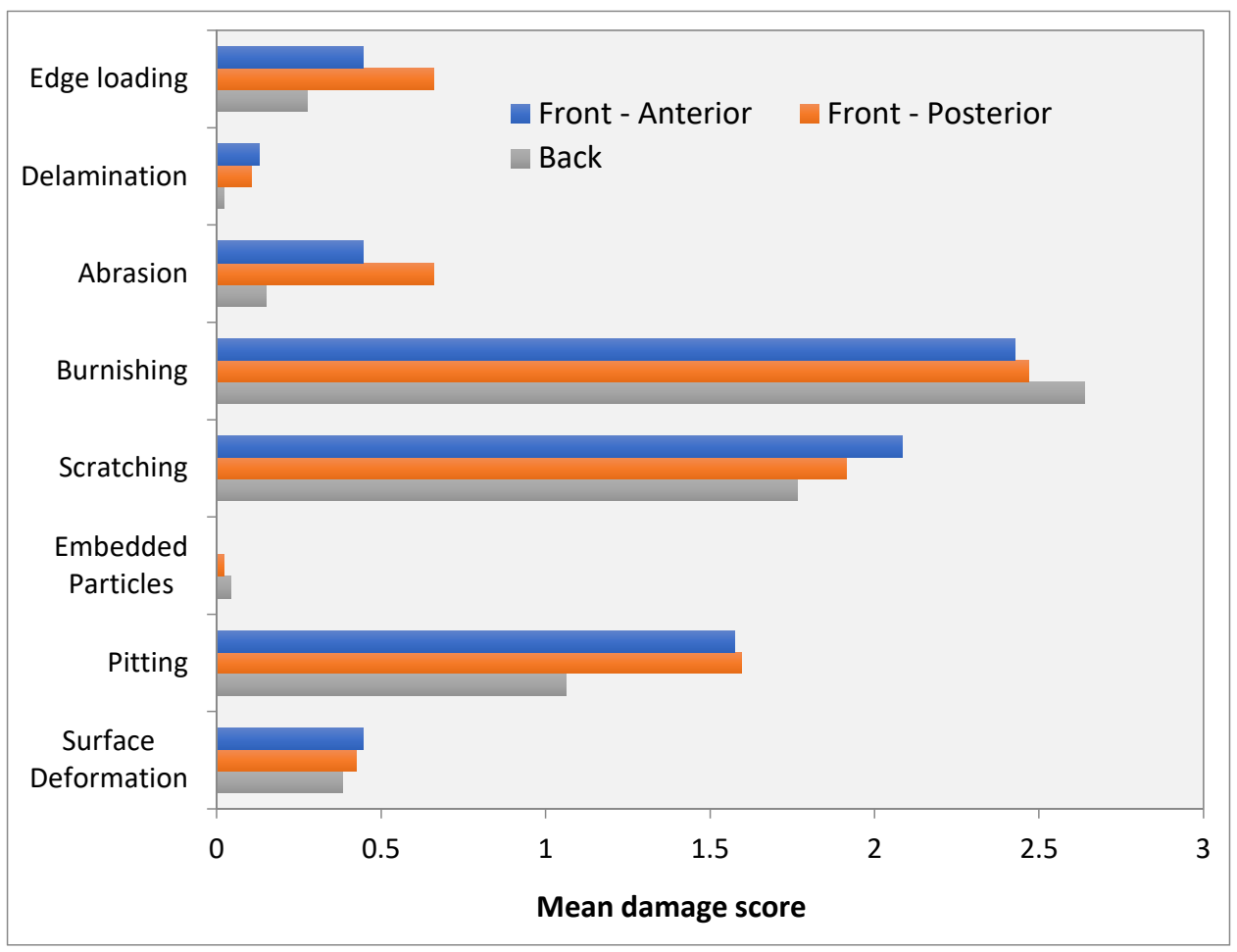

Figure 3. Hood damage score for all parts of the inlay (front-anterior and -posterior; back). 
An ANOVA was conducted to compare damages for the four different bearing sizes. The mean total damage scores did not differ significantly in the four groups in this cohort $(p=0.86$; Figure 4).

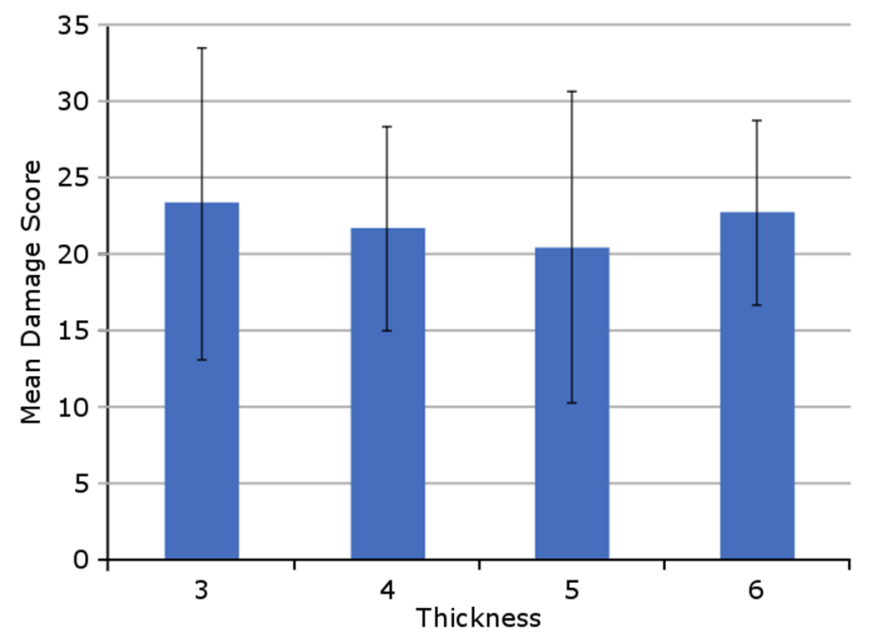

Figure 4. The distribution of the mean total damage score for the four inlay sizes $(n=47)$.

The lowest damage score could be seen at the backside of the implant, while front-anterior and front-posterior showed comparable results. As expected, the total damage score increased with the ongoing time to revision (Figure 5), although there was only a weak correlation $\left(R=0.3 ; R^{2}=0.09\right.$, $p<0.05)$.

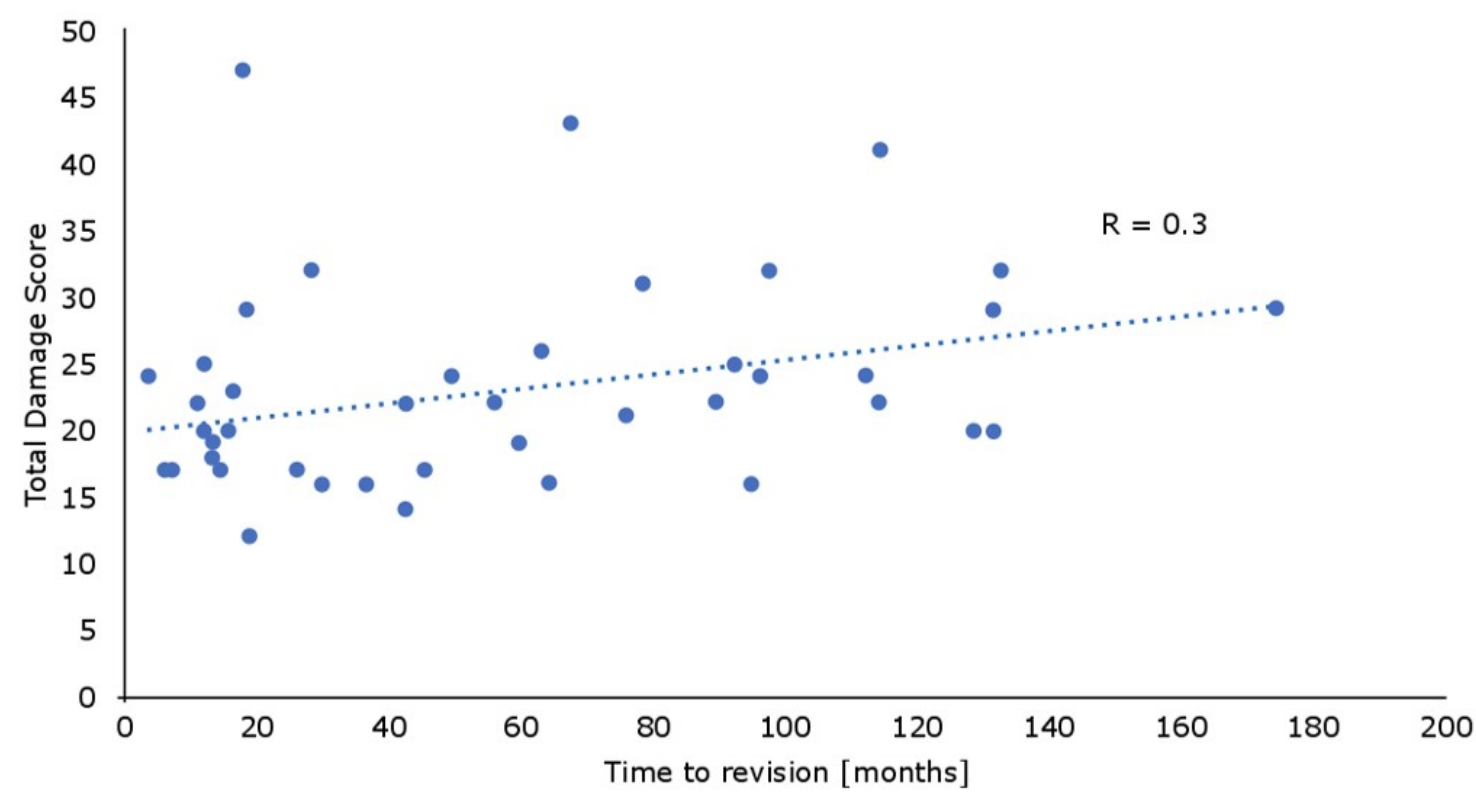

Figure 5. With the increasing time to revision, the total damage score increased $(p<0.05)$, but this correlation was weak $(\mathrm{R}=0.3)$.

The linear wear of the inlay increased with time (Figure 6). 


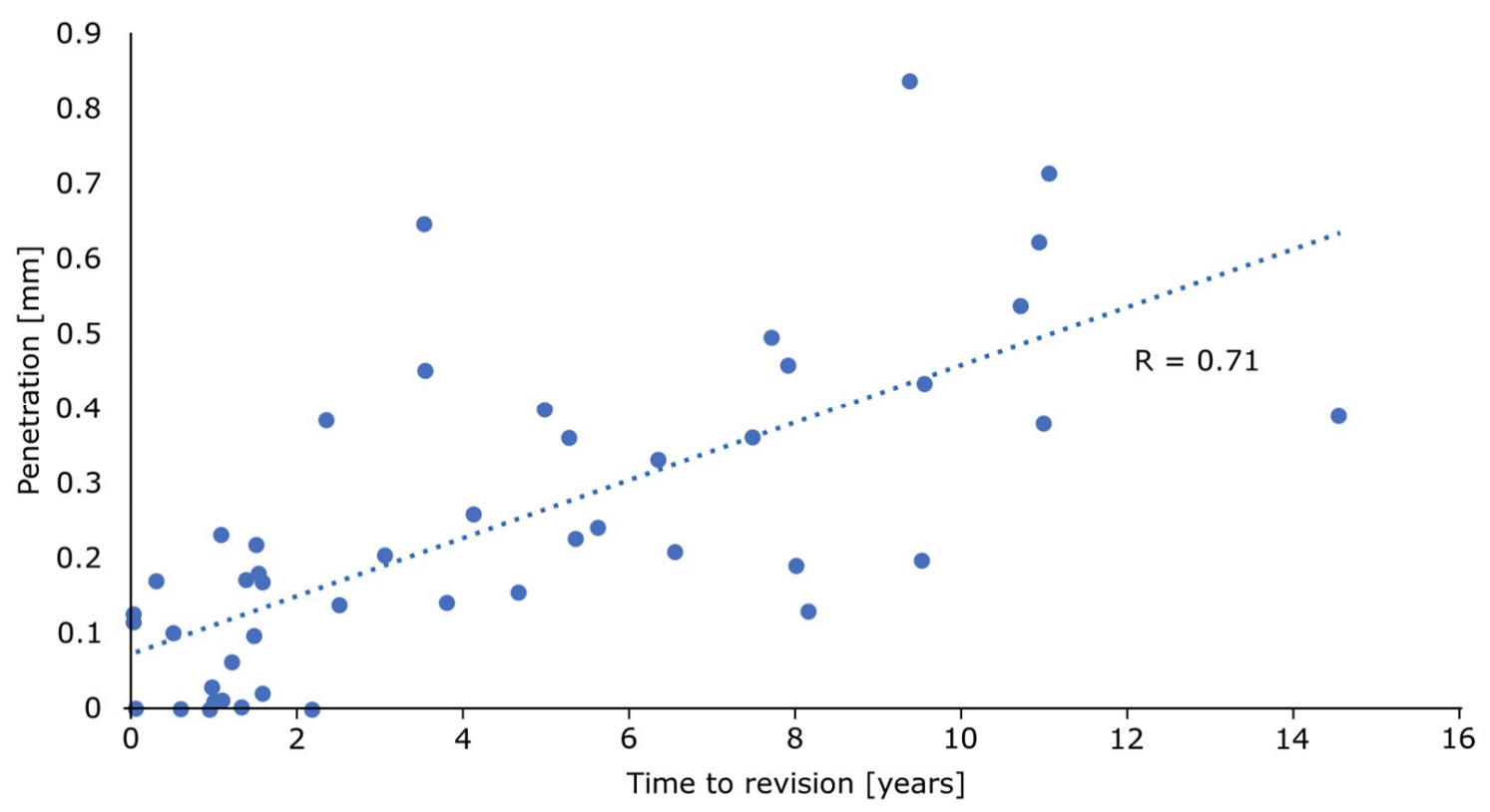

Figure 6. There is a strong correlation between the time to revision and penetration $(\mathrm{R}=0.71 ; p<0.001$; $n=47)$.

A Shapiro-Wilk test was performed to check for normal distribution with a $\mathrm{p}>0.05$. The Shapiro-Wilk test revealed non-normal distribution and a Wilcoxon signed-rank test was performed for the subsequent analyses. The low-thickness inlays showed a mean penetration of $37.5 \mu \mathrm{m}$ per year, whereas the high-thickness inlays exhibited lower penetration of $27.6 \mu \mathrm{m}$ per year, the difference was not significant (Figure 7, p = 0.173).

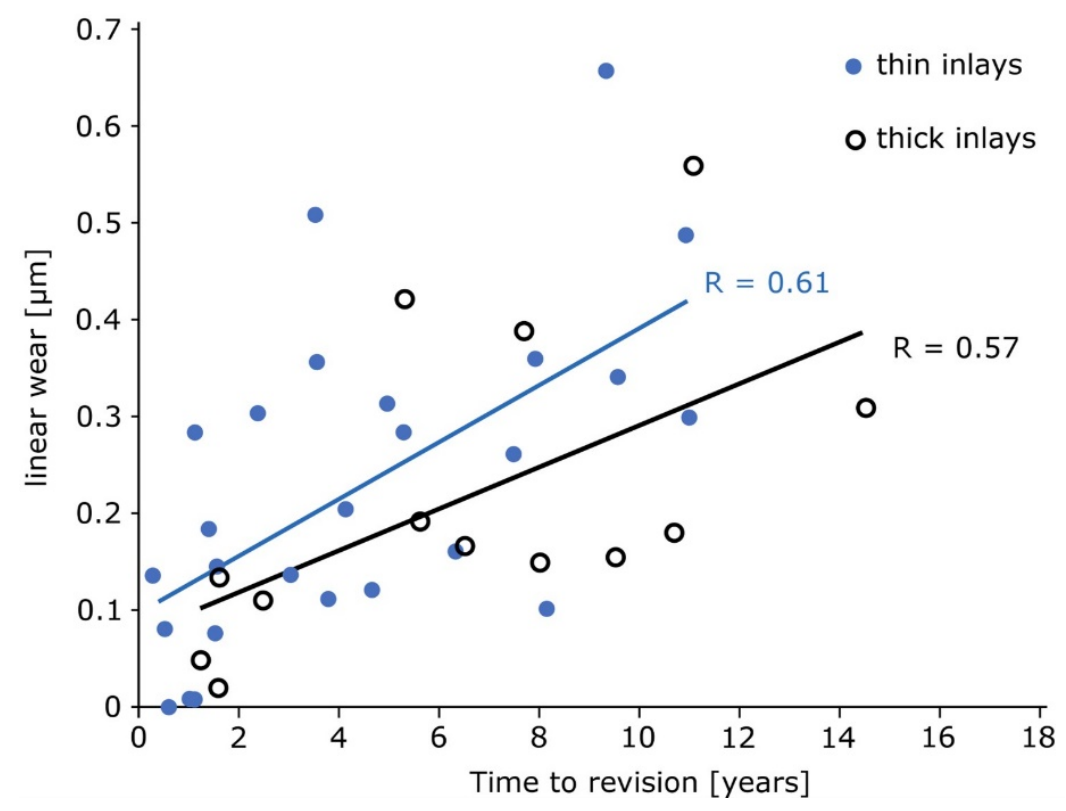

Figure 7. Linear wear shows comparable results for thin, as well as thick inlays $(\mathrm{p}=0.173)$.

The total damage score and the linear penetration did not show any correlation $(R=0.137$; $p=0.383)$. The approximated wear volume for all inlays increased over time $(R=0.53, p=0.001)$. The mean approximated wear volume for low-thickness inlays was $26.3 \mathrm{~mm}^{3}$ per year $(R=0.59$, $\mathrm{p}=0.001)$ and for high-thickness inlays $18.0 \mathrm{~mm}^{3}$ per year $(0.53, \mathrm{p}=0.001)$ without significant differences (Figure 8, $\mathrm{p}=0.196$ ). 


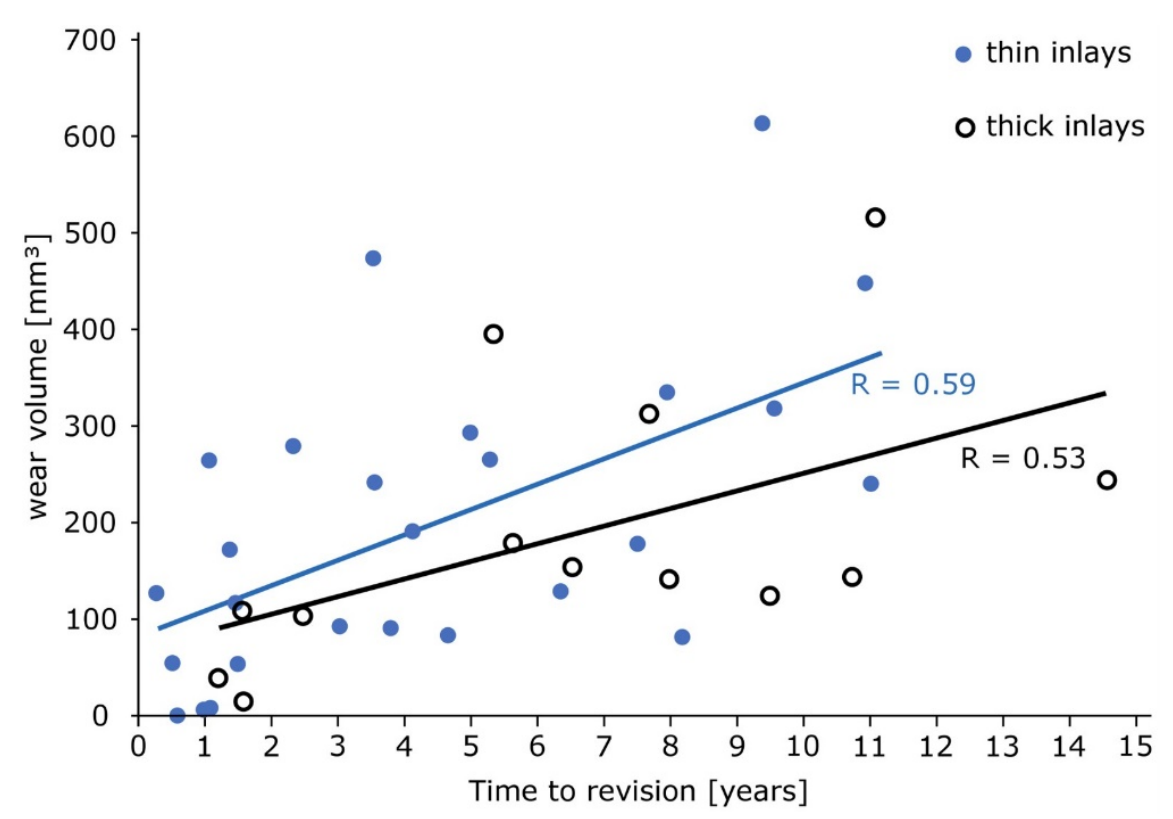

Figure 8. Thin and thick inlays show comparable wear volumes over time $(\mathrm{p}=0.196)$.

Finally, there was no significant difference in survival time for the two different groups (Figure 9, $p=0.264)$.

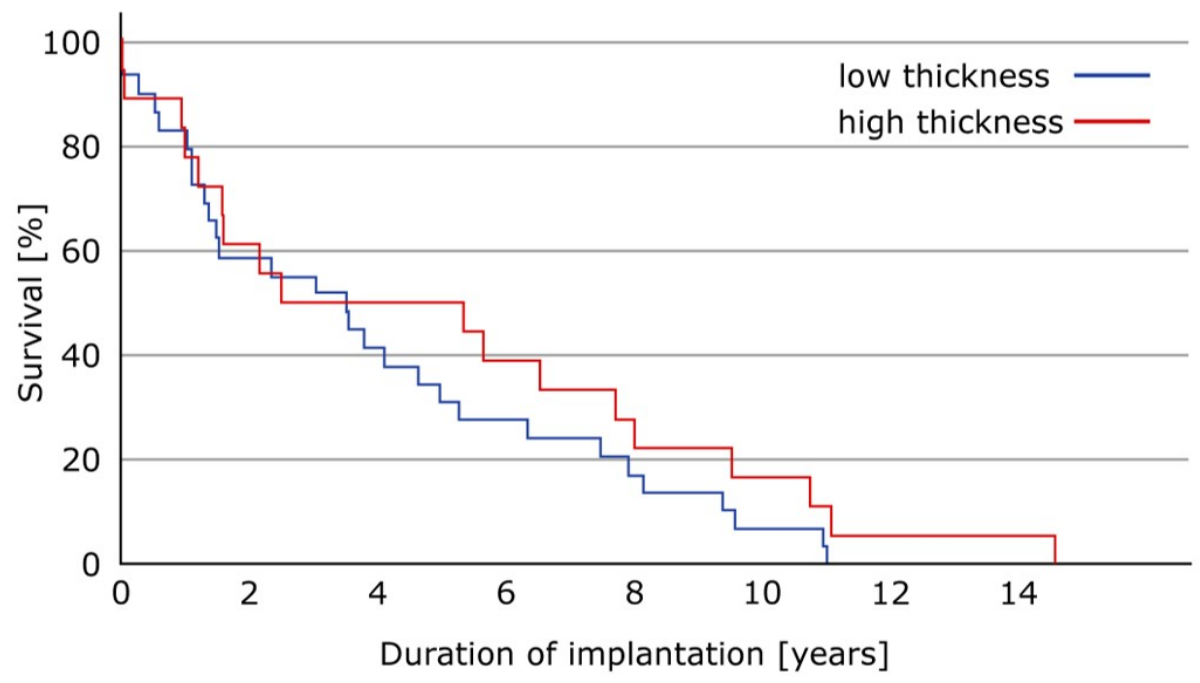

Figure 9. Kaplan-Meier blot for the two groups, showing no significant differences in survival $(\mathrm{p}=0.264)$.

\section{Discussion}

In this retrieval analysis, the most common damage forms in descending order were burnishing, scratching, and pitting. This is consistent with earlier studies showing the same pattern of damage in total knee replacement [22,23]. However, also different damage patterns have been described and the pattern seems to be strongly influenced by the type of bearing [24,25]. In fully congruent meniscal bearing, extreme forms of damage such as edge loading are only expected to occur in small subsets of specimen, as they are rarely seen in cases of dislocation of subluxation of the inlays [26], while others such as embedded particles are also associated with the implantation technique. In this cohort, most types of damage distributed equally between the different surfaces (anterior, posterior, and back-i.e., tibial articulating surface). Abrasion was rarely seen at the backside which is to be 
expected, given the fully congruent nature of the tibial articulating portion of the bearing. In UKA as well as TKA, it has been advised against the use of thin inlays, due to the higher risk of thinning, increased wear, and risk for revision favoring the use of thicker inlays [27,28]. However, in our study we could find no such connections. While the linear penetration and the approximated volumetric wear rates were higher for the low thickness bearings, these findings were insignificant. Likewise, the survival rates for both groups showed comparable results. The total damage assessed by the Hood score and the penetration per month did not show any correlation. While counter-intuitive, this has been described by other groups before $[29,30]$.

The penetration of $37.5 \mu \mathrm{m}$ per year for low thickness and $27.6 \mu \mathrm{m}$ per year for high thickness bearings is in range with studies published previously. Engh et al. described rates of approximately 50-60 $\mu \mathrm{m}$ per year for the medial and $30 \mu \mathrm{m}$ for the lateral compartment in a type of total knee replacement [22], which is in line with results reported by Kop and Swarts who reported $54 \mu \mathrm{m}$ for the superior surface of LCS knees [31]. For the Oxford unicompartmental knee arthroplasty, Horsager et al. described wear rates of 40 and $50 \mu \mathrm{m}$ per year for the cemented and cementless versions, respectively, which is slightly lower than what we have seen in our cohort [32]. The aforementioned study was conducted using the radiostereometic analysis (RSA), which has been shown to produce accurate results in total knee replacement wear analysis [33,34]. However, no study comparing wear assessed by RSA and subsequently by the retrieval analysis has been conducted so far, to the best of our knowledge, and a certain error in measurement has to be accepted. In the present study, a direct measurement of the retrieved inlays was possible, which can be assumed as the most valid form to measure inlay penetration.

There are several limitations to our study: Since not all of the prostheses were implanted in our hospital, we could not assess clinical and radiological data. We analyzed both anatomical and non-anatomical bearings and the polyethylene used in the different generations of bearings does differ. Furthermore, as is the case for most retrieval studies, this was conducted as a retrospective analysis. Accordingly, the radiological examinations were not standardized to the need of the analyzer but to the need of the clinician. Hence, we could not properly assess pre- and post-operative valgus/varus, which might have an influence on the types and extent of damage. Furthermore, a correlation between patient satisfaction and experimental findings could not be investigated. Finally, as knee revision surgery is a complex and rarely standardized procedure, damages to the bearing and the rest of the implant can occur during the aforementioned surgery, although the differences between surgically induced damage and damage through wear and tear can be distinguished quite easily as done in this study.

To the best of our knowledge, this is the largest independent series of consecutively retrieved bearings of the medial Oxford unicompartmental knee arthroplasty to date. We could not find any significant differences in the two analyzed groups (high thickness- 5 and $6 \mathrm{~mm}$-and low thickness- 3 and $4 \mathrm{~mm}$-inlays) with regards to damage score, types of damage, penetration, approximated wear rate, and survival time.

\section{Conclusions}

In this retrospective retrieval analysis, we wanted to assess whether bearing thickness influences the clinical outcome and biomechanical aspects, with a special focus on time to revision and wear. We could not find significant differences for low- and high-thickness inlays. This study suggests that inlays with the analyzed bearing thicknesses can safely be used in OUKA without an increased risk for a decreased time to revision due to higher wear.

Author Contributions: Conceptualization, J.A.E. and J.P.K.; methodology, U.M.; software, S.J. and T.W.; validation, J.A.E., U.M., and J.P.K.; formal analysis, J.A.E.; investigation, J.A.E. and J.P.K.; resources, J.P.K.; data curation, J.A.E. and U.M.; writing-original draft preparation, J.A.E.; writing-review and editing, U.M. and J.P.K.; visualization, M.S.; supervision, J.P.K.; project administration, J.P.K. All authors have read and agreed to the published version of the manuscript. 
Funding: This research received no external funding.

Acknowledgments: We would like to thank Linda Stange for language editing the manuscript.

Conflicts of Interest: The authors declare no conflict of interest.

\section{References}

1. Dyrhovden, G.S.; Lygre, S.H.L.; Badawy, M.; Gøthesen, Ø.; Furnes, O. Have the causes of revision for total and unicompartmental knee arthroplasties changed during the past two decades? Clin. Orthop. Relat. Res. 2017, 475, 1874-1886. [CrossRef] [PubMed]

2. Brown, T.S.; Van Citters, D.W.; Berry, D.J.; Abdel, M.P. The use of highly crosslinked polyethylene in total knee arthroplasty. Bone Jt. J. 2017, 99, 996-1002. [CrossRef] [PubMed]

3. Chakravarty, R.; Elmallah, R.D.K.; Cherian, J.J.; Kurtz, S.M.; Mont, M.A. Polyethylene Wear in Knee Arthroplasty. J. Knee Surg. 2015, 28, 370-375. [CrossRef] [PubMed]

4. Annual Report Australian Orthopaedic Association. 2017. Available online: https://aoanjrr.sahmri.com/de/ annual-reports-2017 (accessed on 14 October 2020).

5. Jennings, J.M.; Kleeman-Forsthuber, L.T.; Bolognesi, M.P. Medial unicompartmental arthroplasty of the knee. J. Am. Acad. Orthop. Surg. 2019, 27, 166-176. [CrossRef] [PubMed]

6. Mohammad, H.R.; Strickland, L.; Hamilton, T.W.; Murray, D.W. Long-term outcomes of over 8,000 medial Oxford Phase 3 Unicompartmental Knees-A systematic review. Acta Orthop. 2018, 89, 101-107. [CrossRef] [PubMed]

7. Simpson, D.J.; Gray, H.; D'Lima, D.; Murray, D.W.; Gill, H.S. The effect of bearing congruency, thickness and alignment on the stresses in unicompartmental knee replacements. Clin. Biomech. 2008, 23, 1148-1157. [CrossRef]

8. Kretzer, J.P.; Jakubowitz, E.; Reinders, J.; Lietz, E.; Moradi, B.; Hofmann, K.; Sonntag, R. Wear analysis of unicondylar mobile bearing and fixed bearing knee systems: A knee simulator study. Acta Biomater. 2011, 7, 710-715. [CrossRef]

9. Manson, T.T.; Kelly, N.H.; Lipman, J.D.; Wright, T.M.; Westrich, G.H. Unicondylar knee retrieval analysis. J. Arthroplast. 2010, 25, 108-111. [CrossRef]

10. Pandit, H.; Hamilton, T.W.; Jenkins, C.; Mellon, S.J.; Dodd, C.A.F.; Murray, D.W. The clinical outcome of minimally invasive Phase 3 Oxford unicompartmental knee arthroplasty: A 15-year follow-up of 1000 UKAs. Bone Jt. J. 2015, 97, 1493-1500. [CrossRef]

11. Kim, S.-J.; Bae, J.-H.; Lim, H.C. Factors Affecting the postoperative limb alignment and clinical outcome after oxford unicompartmental knee arthroplasty. J. Arthroplast. 2012, 27, 1210-1215. [CrossRef]

12. Bartel, D.L.; Bicknell, V.L.; Wright, T.M. The effect of conformity, thickness, and material on stresses in ultra-high molecular weight components for total joint replacement. J. Bone Jt. Surg. Am. 1986, 68, 1041-1051. [CrossRef]

13. Bartel, D.L.; Rawlinson, J.J.; Burstein, A.H.; Ranawat, C.S.; Flynn, W.F. Stresses in polyethylene components of contemporary total knee replacements. Clin. Orthop. Relat. Res. 1995, 317, 76-82.

14. Engh, G.A.; Dwyer, K.A.; Hanes, C.K. Polyethylene wear of metal-backed tibial components in total and unicompartmental knee prostheses. J. Bone Jt. Surg. Br. 1992, 74, 9-17. [CrossRef] [PubMed]

15. McAuley, J.P.; Engh, G.A.; Ammeen, D.J. Revision of failed unicompartmental knee arthroplasty. Clin. Orthop. Relat. Res. 2001, 279-282. [CrossRef]

16. Edwards, S.A.; Pandit, H.G.; Ramos, J.L.; Grover, M.L. Analysis of polyethylene thickness of tibial components in total knee replacement. J. Bone Jt. Surg. Am. 2002, 84, 369-371. [CrossRef]

17. Hood, R.W.; Wright, T.M.; Burstein, A.H. Retrieval analysis of total knee prostheses: A method and its application to 48 total condylar prostheses. J. Biomed. Mater. Res. 1983, 17, 829-842. [CrossRef]

18. Mohammad, H.R.; Campi, S.; Kennedy, J.A.; Judge, A.; Murray, D.W.; Mellon, S.J. Long-term in vivo wear of different bearing types used for the oxford unicompartmental knee replacement. Bone Jt. Res. 2019, 8, 535-543. [CrossRef]

19. Cerquiglini, A.; Henckel, J.; Hothi, H.; Rotigliano, N.; Hirschmann, M.T.; Hart, A.J. 3D patient imaging and retrieval analysis help understand the clinical importance of rotation in knee replacements. Knee Surg. Sports Traumatol. Arthrosc. 2018, 26, 3351-3361. [CrossRef] 
20. Tone, S.; Hasegawa, M.; Pezzotti, G.; Puppulin, L.; Sudo, A. Effect of e-beam sterilization on the in vivo performance of conventional UHMWPE tibial plates for total knee arthroplasty. Acta Biomater. 2017, 55, 455-465. [CrossRef]

21. Psychoyios, V.; Crawford, R.W.; O'Connor, J.J.; Murray, D.W. Wear of congruent meniscal bearings in unicompartmental knee arthroplasty: A retrieval study of 16 specimens. J. Bone Jt. Surg. Br. 1998, 80, 976-982. [CrossRef]

22. Engh, G.A.; Zimmerman, R.L.; Parks, N.L.; Engh, C.A. Analysis of wear in retrieved mobile and fixed bearing knee inserts. J. Arthroplast. 2009, 24, 28-32. [CrossRef] [PubMed]

23. Harman, M.; Affatato, S.; Spinelli, M.; Zavalloni, M.; Stea, S.; Toni, A. Polyethylene insert damage in unicondylar knee replacement: A comparison of in vivo function and in vitro simulation. Proc. Inst. Mech. Eng. H 2010, 224, 823-830. [CrossRef] [PubMed]

24. Lu, Y.C.; Huang, C.H.; Chang, T.K.; Ho, F.Y.; Cheng, C.K.; Huang, C.H. Wear-pattern analysis in retrieved tibial inserts of mobile-bearing and fixed-bearing total knee prostheses. J. Bone Jt. Surg. Br. 2010, 92, 500-507. [CrossRef]

25. Ho, F.-Y.; Ma, H.-M.; Liau, J.-J.; Yeh, C.-R.; Huang, C.-H. Mobile-bearing knees reduce rotational asymmetric wear. Clin. Orthop. Relat. Res. 2007, 462, 143-149. [CrossRef]

26. Kendrick, B.J.L.; Longino, D.; Pandit, H.; Svard, U.; Gill, H.S.; Dodd, C.A.F.; Murray, D.W.; Price, A.J. Polyethylene wear in Oxford unicompartmental knee replacement. J. Bone Jt. Surg. Br. Vol. 2010, 92, 367-373. [CrossRef] [PubMed]

27. Lingaraj, K.; Morris, H.; Bartlett, J. Polyethylene thickness in unicompartmental knee arthroplasty. Knee 2011, 18, 165-167. [CrossRef] [PubMed]

28. Pijls, B.G.; Van der Linden-Van der Zwaag, H.M.J.; Nelissen, R.G.H.H. Polyethylene thickness is a risk factor for wear necessitating insert exchange. Int. Orthop. 2012, 36, 1175-1180. [CrossRef]

29. Knowlton, C.B.; Bhutani, P.; Wimmer, M.A. Relationship of surface damage appearance and volumetric wear in retrieved TKR polyethylene liners: Retrieved tkr polyethylene damage patterns and volumetric wear. J. Biomed. Mater. Res. Part B Appl. Biomater. 2017, 105, 2053-2059. [CrossRef]

30. Cerquiglini, A.; Henckel, J.; Hothi, H.; Moser, L.B.; Eskelinen, A.; Hirschmann, M.T.; Hart, A.J. Retrieval analysis of contemporary antioxidant polyethylene: Multiple material and design changes may decrease implant performance. Knee Surg. Sports Traumatol. Arthrosc. 2019, 27, 2111-2119. [CrossRef]

31. Kop, A.M.; Swarts, E. Quantification of polyethylene degradation in mobile bearing knees: A retrieval analysis of the Anterior-Posterior-Glide (APG) and Rotating Platform (RP) Low Contact Stress (LCS) knee. Acta Orthop. 2007, 78, 364-370. [CrossRef]

32. Horsager, K.; Madsen, F.; Odgaard, A.; Fink Jepsen, C.; Rømer, L.; Kristensen, P.W.; Kaptein, B.L.; Søballe, K.; Stilling, M. Similar polyethylene wear between cemented and cementless Oxford medial UKA: A 5-year follow-up randomized controlled trial on 79 patients using radiostereometry. Acta Orthop. 2019, 90, 67-73. [CrossRef] [PubMed]

33. Van Ijsseldijk, E.A.; Valstar, E.R.; Stoel, B.C.; Nelissen, R.G.H.H.; Reiber, J.H.C.; Kaptein, B.L. The robustness and accuracy of in vivo linear wear measurements for knee prostheses based on model-based RSA. J. Biomech. 2011, 44, 2724-2727. [CrossRef]

34. Van Ijsseldijk, E.A.; Harman, M.K.; Luetzner, J.; Valstar, E.R.; Stoel, B.C.; Nelissen, R.G.H.H.; Kaptein, B.L. Validation of a model-based measurement of the minimum insert thickness of knee prostheses: A retrieval study. Bone Jt. Res. 2014, 3, 289-296. [CrossRef]

Publisher's Note: MDPI stays neutral with regard to jurisdictional claims in published maps and institutional affiliations.

(C) 2020 by the authors. Licensee MDPI, Basel, Switzerland. This article is an open access article distributed under the terms and conditions of the Creative Commons Attribution (CC BY) license (http://creativecommons.org/licenses/by/4.0/). 